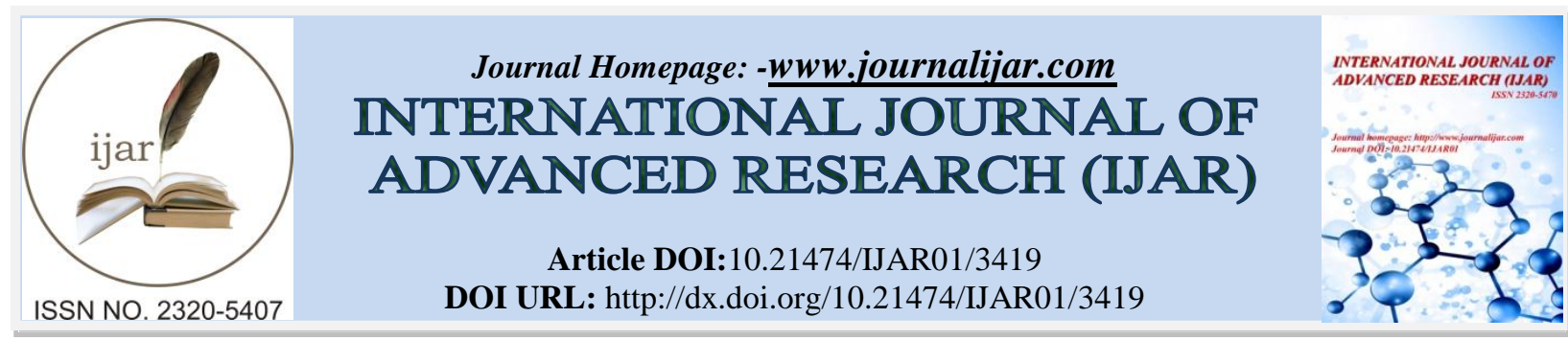

RESEARCH ARTICLE

\title{
EVALUATION OF COINCIDENCE OF FACIAL MIDLINE TO DENTAL MIDLINE AND MAXILLARY MIDLINE TO MANDIBULAR MIDLINE IN UNDERGRADUATE STUDENTS.
}

Soham Mavani, Ramesh TR, Nikunj Patel and Vilas Patel.

\section{Manuscript Info}

Manuscript History

Received: 17 December 2016

Final Accepted: 15 January 2017

Published: February 2017

Key words:-

Facial Midline, Dental Midline, Maxillary and Mandibular midline, Esthetics.

\begin{abstract}
Aim: To evaluate coincidence of Facial midline with Dental midline and Maxillary midline with Mandibular midline in undergraduate students of Narsinhbhai Patel Dental College and Hospital, Visnagar.

Materials and Methods:A total of 200 Undergraduate students with the age range from 18 to 24 were selected randomly for the study. The patient having $2^{\text {nd }}$ molar to $2^{\text {nd }}$ molar present were included in the study. However patients having midline diastema, congenital or acquired defect were excluded. The patients were examined by 2 examiners to check if facial midline wascoincide with dental midline and maxillary midline was coincide with mandibular midline or not.

Result: The results of the present study showed that 180 Patient's (90\%) maxillary midline coincide with the facial midline. Among 20 patients, 14 patient's $(70 \%)$ had facial midline shift towards right side and 6 patients had facial midline shift towards left side.129 Patient's (64.5\%) maxillary midline coincide with mandibular midline.

Conclusion: Maxillary midline is coincide with the philtrum and can be used as a guide for establishing Maxillary dental midline while fabricating fixed prosthesis or removable prosthesis. Maxillary midline is partly coincide with the mandibular midline.
\end{abstract}

Copy Right, IJAR, 2017,. All rights reserved.

\section{Introduction:-}

Smile is the first outline of your personality and it has been accepted that it is the best gift any one can give.The balance smile midline has great importance.The balance smile depends on the coincidence of facial and dental midlines respectively.The facial midline is defined by the landmarks such as nose, philtrum and chin aligned in a straight line.It should be in the center of face and should coincide with the dental midline.The dental midline is the mid sagital line of maxillary and mandibular arches when teeth are in maximum intercuspation. ${ }^{1}$

Dental midline is the vital element in smile design and should be parallel to the long axis of the face. Furthermore it should be perpendicular to Incisal plane and perpendicular to papilla. ${ }^{2}$ Establishing dental midline parallel to that of face is the initial step while fabricating fixed or removable prosthesis. ${ }^{3}$ If it is in harmony with facial component it significantly contributes to the aesthetics of the face. This will give patient a feeling of symmetry and balance.

Complete dentures must be attractive and natural in appearance. An important consideration in arrangement of the anterior teeth is the matter of equilibrium. Dental midline is an imaginary line that will separate the two maxillary central incisors. During complete denture fabrication or fixed prosthesis, we consider the philtrum as a guide for midline of the maxillary incisors. The dental literature fails to disclose the data of any research considered to provide 
information as to how nature position the natural anterior teeth in relation to the anatomic center line of the face. ${ }^{4}$ So aim of the present study is to check the coincidence of facial midline to dental midline and also to check the coincidence of maxillary midline to the mandibular dental midline.

\section{Materials and Methods:-}

A Total of 250 dentate patients were selected from Narsinhbhai Patel Dental College and Hospital, Visnagar, Gujarat. The standards for selection of participants include undergraduate students from first year to final year and interns with age range from 17 to 25 years. All of them had permanent dentition from $2^{\text {nd }}$ molar to $2^{\text {nd }}$ molar in maxillary arch. There was random selection for male and female participants, no fixed proportion was proposed. The patients with midline diastema and congenital or acquired maxillofacial deformity were excluded. The patients undergone any orthodontic treatment were also excluded in the study. A written informed consent was obtained from each selected participant.

All the participants were examined by 2 examiners separately. To avoid eye fatigue both the examiners examined 50 participants per day. The participants were observed to check if maxillary dental midline coincides with facial midline. The facial midline was inspected by marking points between mid-deepest part of the till middle of the anterior most part of chin including center of philtrum with the help of scale or dental floss.

As a part of the routine examination, a specially set form was filled out by the examiner. The form required that two questions to be answered:

1. Does the dental midline (between the maxillary central incisors) coincide with the facial median line (using the philtrum as the guide)?

Yes No

2. Does the midline of the maxillary teeth coincide with the midline of the mandibular teeth?

$$
\text { Yes No }
$$

\section{Results:-}

200 undergraduate students were evaluated for coincidence of facial midline with dental midline at Narsinhbhai Patel Dental College and Hospital, Visnagar,S Gujarat and results were obtained as follows. Philtrum was the guide to check the coincidence of the midline. Data was analyzed with descriptive statistical test.

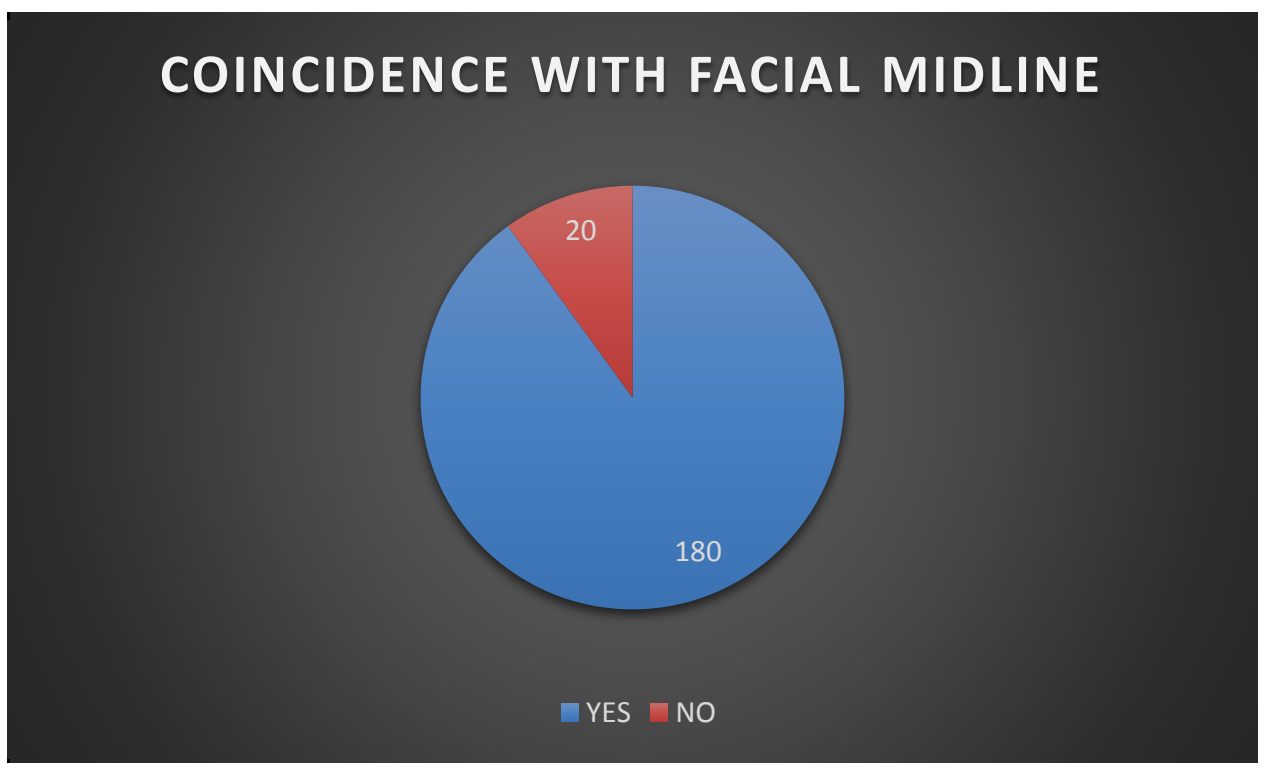

Graph 1:-Coincidence of Facial Midline with Dental Midline

Graph 1 showed Coincidence of Facial midline and Dental midline in patients in which among 200 patients 180 patient's $(90 \%)$ facial midline coincide with the dental midline (Figure 1) and 20 patient's $(10 \%)$ midline did not coincide with the facial midline (Figure 2). 


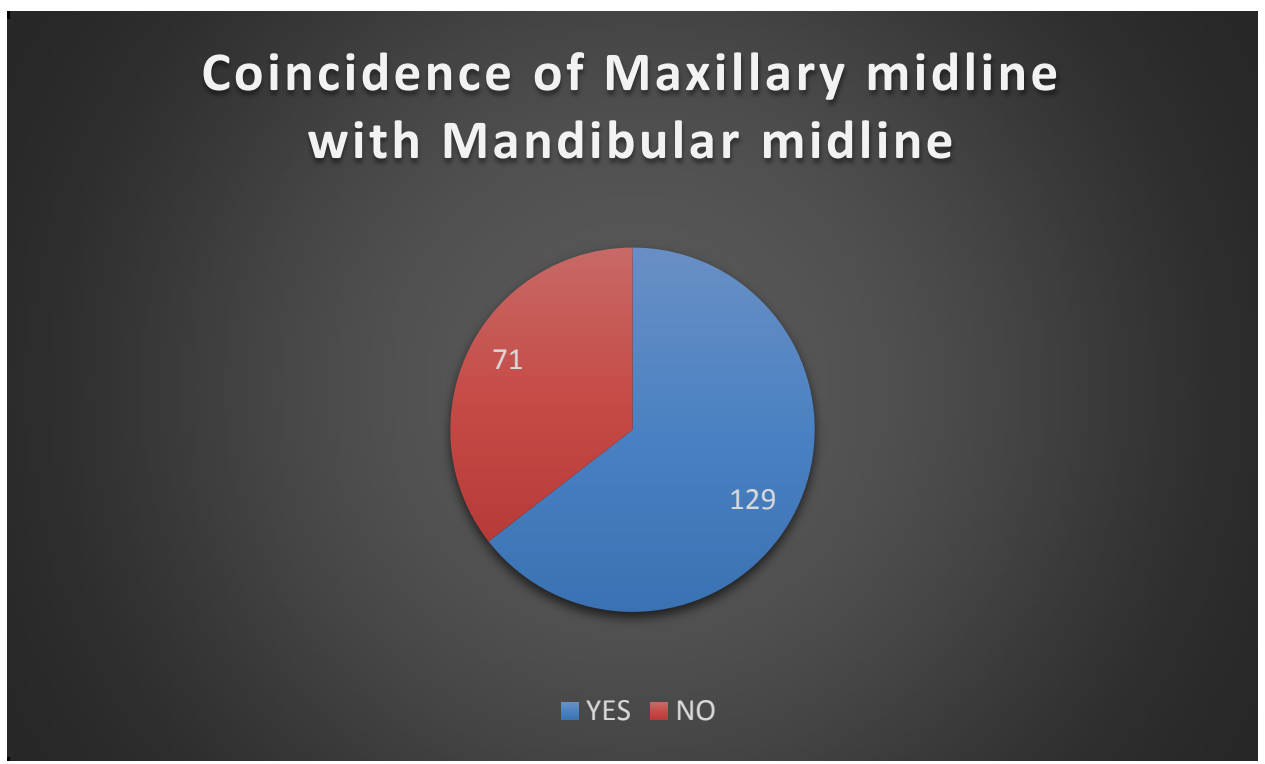

Graph 2:-Coincidence of Maxillary Midline with Mandibular Midline

Graph 2 showed that 129 patient's (64.5\%) maxillary midline coincide with mandibular midline (Figure 3)and 71 patient's (35.5\%) maxillary midline did not coincide with mandibular midline (Figure 4).

Table 1:-Facial and dental shift of midline towards right and left

\begin{tabular}{|c|c|c|c|c|}
\hline & \multicolumn{2}{|c|}{ FACIAL SHIFT } & \multicolumn{2}{c|}{ DENTAL SHIFT } \\
\cline { 2 - 5 } & Right & Left & Right & Left \\
\hline Frequency & 14 & 6 & 39 & 32 \\
\hline Percentage \% & 70 & 30 & 54.93 & 45.07 \\
\hline
\end{tabular}

Table 1 showed that Midline shift of patients towards right and left side. It showed that for facial midline to dental midline shift is more toward right side than the left side. For Dental midline shift, more patients had midline shift towards right side than the left side.

Table 2:-Facial Midline shift in distance

\begin{tabular}{|c|c|c|c|c|}
\hline Distance & $\begin{array}{c}\text { Towards } \\
\text { Right }\end{array}$ & $\begin{array}{c}\text { Percentage } \\
\text { \% }\end{array}$ & $\begin{array}{c}\text { Towards } \\
\text { left }\end{array}$ & Percentage \% \\
\hline $1 \mathrm{~mm}$ & 8 & 4 & 2 & 1 \\
\hline $2 \mathrm{~mm}$ & 4 & 2 & 3 & 1.5 \\
\hline $3 \mathrm{~mm}$ & 2 & 1 & 1 & 0.5 \\
\hline
\end{tabular}

Table 2 showed facial midline shift with distance towards right and left side. It showed that facial midline shift more towards right side than left side.

Table 3:-Dental midline shift in distance

\begin{tabular}{|c|c|c|c|c|}
\hline Distance & Towards right & $\begin{array}{c}\text { Percentage } \\
\text { \% }\end{array}$ & Towards left & $\begin{array}{c}\text { Percentage } \\
\text { \% }\end{array}$ \\
\hline $1 \mathrm{~mm}$ & 6 & 3 & 11 & 5.5 \\
\hline $2 \mathrm{~mm}$ & 23 & 11.5 & 16 & 8 \\
\hline $3 \mathrm{~mm}$ & 7 & 3.5 & 4 & 2 \\
\hline $4 \mathrm{~mm}$ & 3 & 7.7 & 1 & 0.5 \\
\hline
\end{tabular}

Table 3 showed Dental midline shift with distance towards right and left side. It showed that dental midline shift more towards right side than left side.

\section{Discussion:-}

Graph 1 showed that among 200 patients 180 patient's (90\%) facial midline coincide with the dental midline and 20 patient's (10\%) midline did not coincide with the facial midline. It indicates that almost all patients midline is coincides with the philtrum of the patients. 
Graph 2 showed that 129 patients' (64.5\%) maxillary midline coincide with mandibular midline and 71 patients' (35.5\%) maxillary midline did not coincide with mandibular midline. It indicates that not all patients maxillary midline coincide with the mandibular midline.

Table 1 showed that among 20 patients, 14 patients (70\%) had facial midline shift towards right side and 6 patients (30\%) had facial midline shift towards left side. It indicates that more midline shifts noted towards right side than left side. Among 71 patients, 39 patients (54.93\%) had dental midline shift towards right side and 32 patients $(45.07 \%)$ had dental midline shift towards left side. It indicates that dental midline shift found more on right side than left side.

Table 2 showed facial midline shift with distance towards right and left side. It showed that towards right side among 14 patients, 8 patients' had midline shift of $1 \mathrm{~mm}, 4$ patient had midline shift of $2 \mathrm{~mm}$ and 2 patients had midline shift of $3 \mathrm{~mm}$. Towards left side among 6 patients 2 patients had midline shift of $1 \mathrm{~mm}, 3$ patients had midline shift of $2 \mathrm{~mm}$ and 1 patient had midline shift of $3 \mathrm{~mm}$.

Table 3 showed Dental midline shift with distance towards right and left side. It showed that among 39 patients towards right side 6 patient showed midline shift of $1 \mathrm{~mm}, 23$ patients showed midline shift of $2 \mathrm{~mm}, 7$ patients showed midline shift of $3 \mathrm{~mm}$ and 3 patient showed midline shift of $4 \mathrm{~mm}$. Towards left side among 32 patients, 11 patients showed midline shift of 1mm, 16 patients showed midline shift of $2 \mathrm{~mm}, 4$ patients showed midline shift of $3 \mathrm{~mm}$ and 1 patient showed midline shift of $4 \mathrm{~mm}$.

Facial symmetry is one of the facial aesthetic characteristic. Attractiveness of the face depends on alignment, symmetry and proportion of face. To achieve a balance smile while fabricating fixed or removable prosthesis is mandatory. The results of the present study are in agreement with the results obtained in the study conducted in city of Riyadh, Saudi Arabia. ${ }^{5}$ They have found $88.10 \%$ subjects showing coinciding maxillary dental midline with facial midline. Similar results were obtained in another study done by Miller. ${ }^{6}$

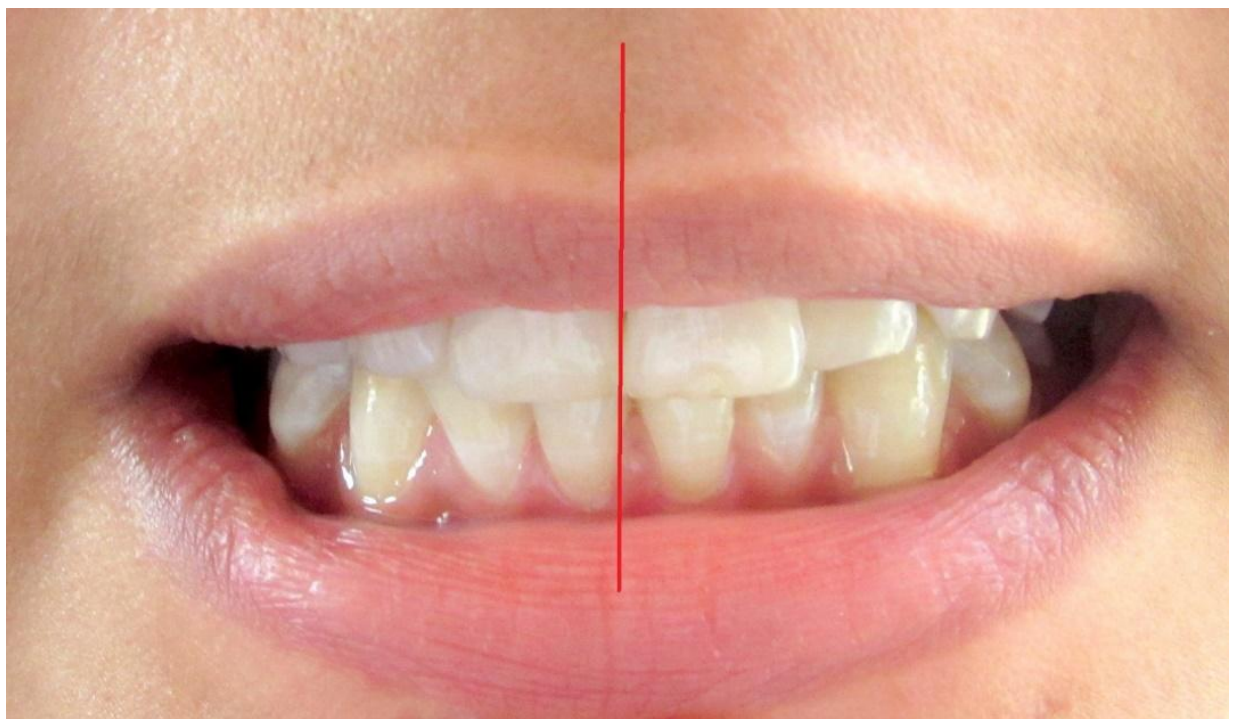

Figure 1:-Facial midline coincide with Maxillary midline 


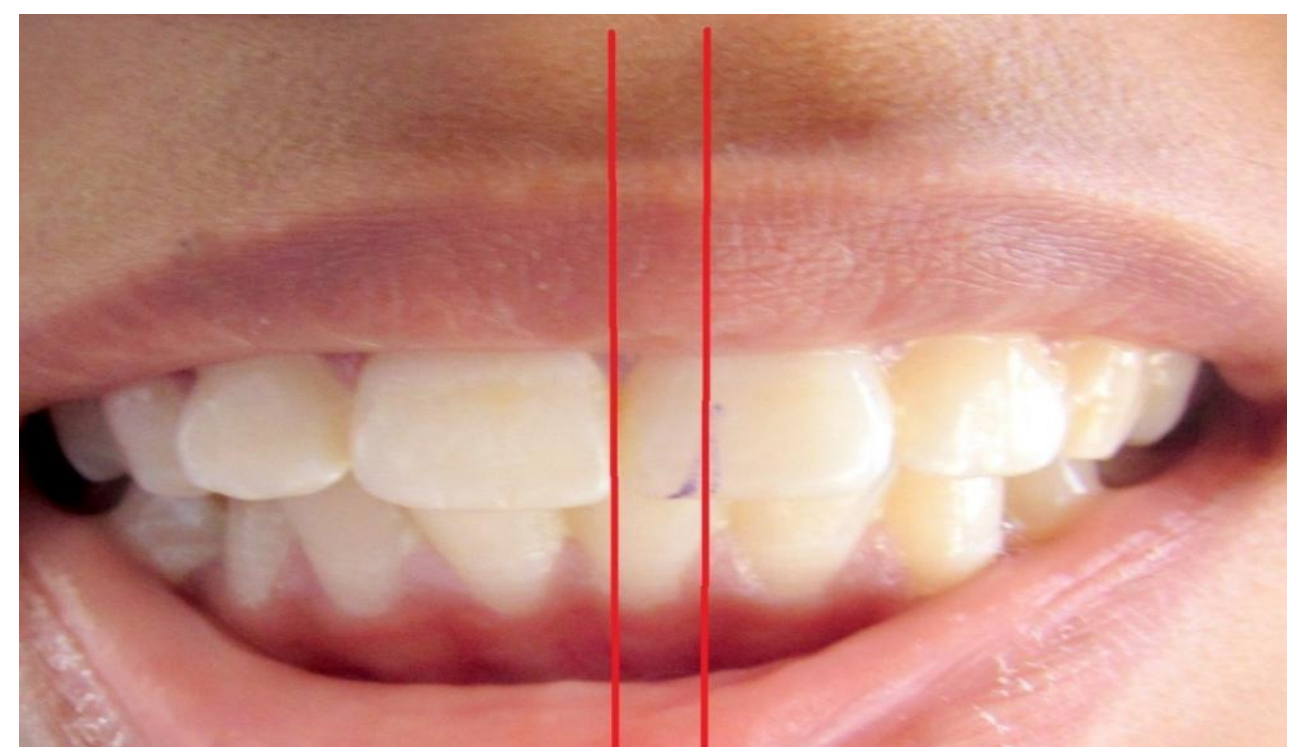

Figure 2:-Facial midline not coincide with Maxillary midline

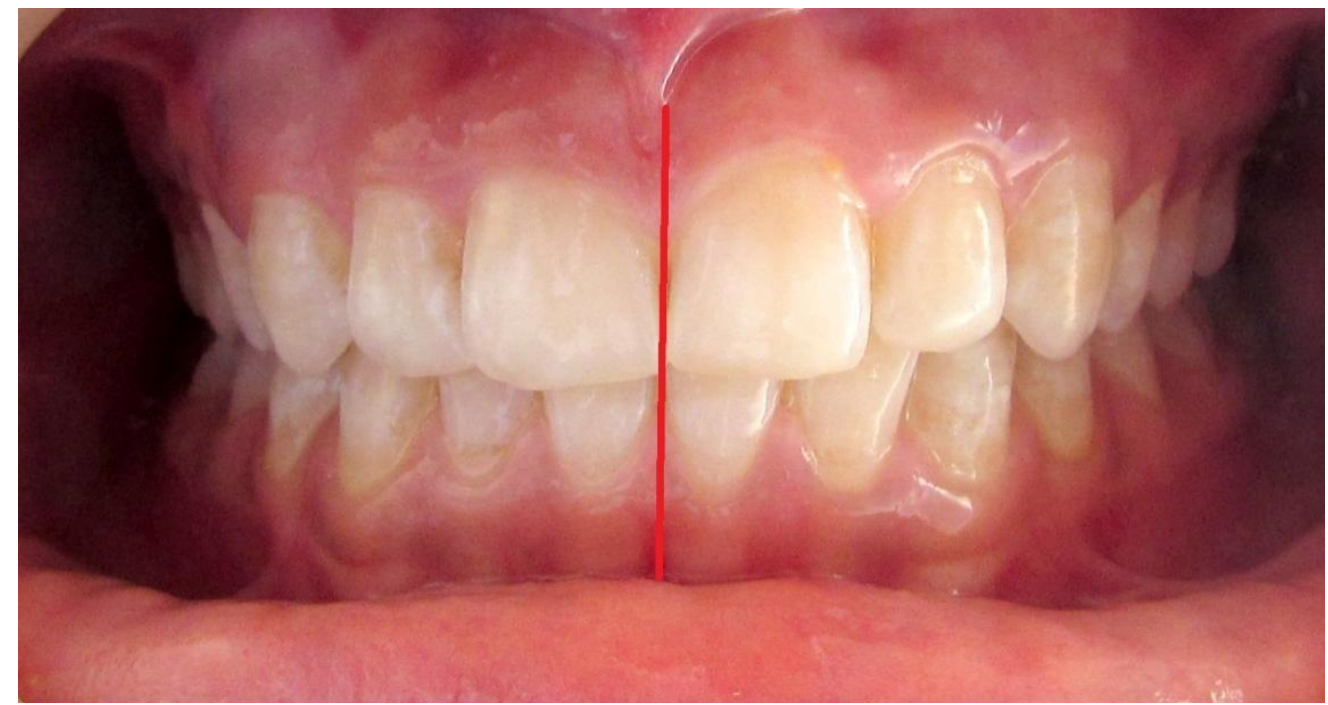

Figure 3:-Maxillary midline coincide with Mandibular midline

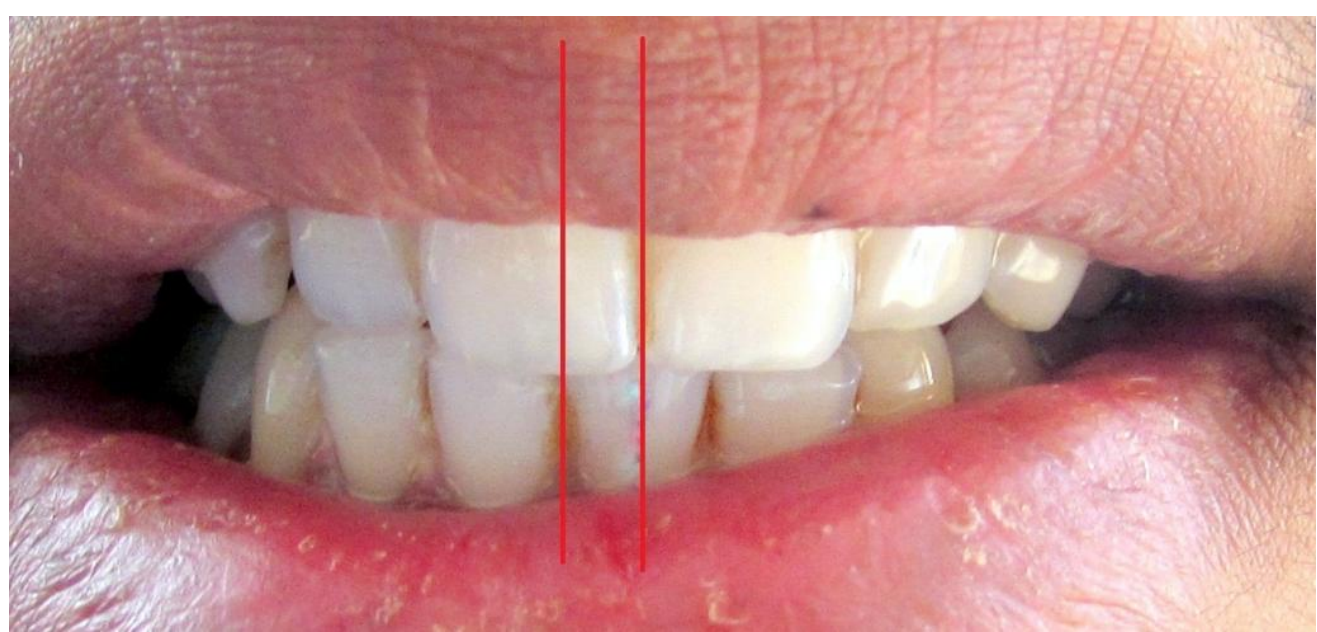

Figure 4:-Maxillary midline not coincide with Mandibular midline 


\section{Conclusion:-}

With the limitation of this study it was concluded that

1. Maxillary midline is coincide with the philtrum and can be used as a guide for establishing maxillary dental midline while fabricating fixed prosthesis or removable prosthesis.

2. Maxillary midline is partly coincide with the mandibular midline.

\section{References:-}

1. Khan MF, Qamar K, Naeem S. Coincidence of facial midline with dental midline. Pakistan Oral \& Dental Journal. 2014;34(2):355-357.

2. Beyer JW, Lindauer SJ. Evaluation of dental midline position. SeminOrthod 1998; 4: 146-52.

3. Zhang YF, Xiao L, Juan Li et al. Young People's Esthetic Perception Of Dental Midline Deviation. Angle Orthodont 2010: 80; 3-5.

4. Miller EL, Bodden WR Jr. and Jamison HC. A study of the relationship of the dental midline to the facial median line. J Prosthet Dent 1979;41(6):657-660.

5. Rhodes G. The evolutionary psychology of facial beauty. Annu rev psychol2006; 57: 199-226.

6. Shyagali TR, Chandralekha B, Bhayya DP, Kumar S, Balasubramanyam G. Are ratings of dentofacial attractiveness influenced by dentofacial midline discrepancies? AustOrthod J 2008; 24(2): 91-5. 